Cragg argues that it is important that jurisprudence develops in a way that will be of most use to the users of the community care services. The article also outlines other particular areas of interest to the project and the non-casework consultancy services which it is able to supply.

\title{
COMMENT
}

It is useful to know of the work of the Public Law Project concerning the judicial review of decision-making in relation to the health service and care in the community and it has already begun to make its mark in this field. The Public Law Project can be contacted at Charles Clore House, I 7 Russell Square, London WC $\mathrm{W}_{1}$ B 5 DR. Tel. or 7 I-436 og64.

Age Concern England,

London

\section{Ageing and the Family in Australia John McCormack}

International Year of the Family, Australian Journal on Ageing, Special issue, 13, 4 (1994), I 53-201.

To commemorate 1994 as the International Year of the Family (IYF), the Australian fournal on Ageing $(A J A)$ published this special issue to highlight ageing in the context of the family. The issue begins with a feature article which reviews Australian research and knowledge on ageing and families. It has four sections, each with two or three papers, addressing various ageing and family issues: elder-care, marriage and family support, women's issues in Asia, and the dynamics of caregiving.

The feature article by Kendig on Australian research achievements in ageing and family issues reviews publications listed in the Australian Ageing Research Directory, the $A \mathcal{F} A$, and the Proceedings of the Australian Association of Gerontology. This review shows that publications in the topic emerged in the I950s and that listings in the Directory alone have grown to more than fifty in I 993 , with the majority of these concerning caregiving. The Ageing and the Family project carried out at the Australian National University during $1980-5$ was a landmark study and found, among other things, that older people are characterised more by their diversity and family contributions than by dependence. Kendig reviews the findings under several themes. On care-giving, the findings are similar to those overseas, especially in relation to the key role of daughters and the adverse effects of care-giver stress. On social 
factors and issues, the depth of research into areas such as family relationships, elder abuse and social diversity, contrasts with the absence of research on social class or sexual intimacy. Health as a topic area is well represented, as is participation in international comparative projects. Policy studies, with a focus on family carers, have emerged from the Australian Federal Government's Aged Care Reviews and in the course of implementation of the Home and Community Care Programme in 1985 .

Kendig concludes the article by identifying five needs for further research: the use of sound multi-disciplinary theory; to examine the views of all individuals within family units and their effect on interactions; for more qualitative studies to gain insight into these complex relationships; for more longitudinal and historical studies to examine the dynamics and shifts in the balance of responsibility between self-care, informal care and formal care; and greater use of the family as an explanatory factor in other areas of gerontology, such as retirement incomes or individual health promotion. Kendig sees the current South Australian Longitudinal Study of Ageing as well placed to respond to these priorities, and is optimistic regarding the future of ageing and family research in Australia.

The Eldercare Forum comprises three papers which cover research, and employer and employee perspectives on issues of work and caring. In March I990 Australia announced its intention to ratify the International Labour Organisation's Convention i56, Workers with Family Responsibilities, and the three papers refer to this policy commitment. In the first article, Russell reports the findings of a survey of 8,662 employees from five large firms (four private and one public) concerning their family responsibilities for elder-care. The survey found that between 15-33 percent of employees had a dependent elderly parent or relative, and between $50-60$ percent of all employees expected elder-care to be a problem in the next fifteen years; the average number of days taken off work per year was two. Russell found that gender was not a significant factor in taking leave for elder-care responsibilities. He concludes that elder-care already has an impact on business and he suggests various initiatives which employers and government could take, such as information and referral programmes.

A paper by Triulzi questions whether it is the employer's responsibility to provide elder-care. Noting the minimal response of Australian business to date, she argues on efficiency grounds that it is in the employer's interest to consider having an elder-care policy because of the adverse effects that unplanned family leave absence can have on productivity. Similarly, if a firm is to be globally competitive 
it needs to retain its skilled workers, for which an elder-care policy can be an incentive. She concludes by outlining a range of options such as education, information services and flexible work scheduling, which she believes should be part of a partnership between employees and employers. The final paper in this section by Rubin examines family leave from both the union and employee perspectives. She discusses a test case for five days paid family leave which was lodged by the Australian Council of Trade Unions to the Industrial Relations Commission. While supported by community groups, the Federal and State governments and major employer groups opposed the claim as an entitlement, preferring it to be negotiated at the individual enterprise. Rubin is critical of this 'grace and favour' approach and predicts growing inequity between workers depending on bargaining strength.

The third section of the journal looks at Marriage and Family Support. Rowland's paper on family change and marital status discusses trends in marriage and divorce of older people. He concentrates on marital status as a key indicator of family resources for care and support in later life, and uses a new methodology for projecting marital status which goes beyond cross-sectional analysis by tracing cohort life lines in census data. His results show marked cohort differences for men and women: far greater proportions of men in all cohorts from 6o-84 years are likely to be married while women, particularly after age 75, are far more likely to be widowed. While early widowhood seems to be on the wane, indicating greater potential for increased family resources, Rowland predicts this increase will be seriously weakened in the longer term by the continued spread of divorce.

The second paper by Tilse examines long term marriage and transitions to long term care. Using a qualitative approach, she describes the experiences of 23 people who had placed a long term partner into a residential facility in the previous 18 months. She narrates the feelings of overwhelming sadness, tremendous loss and the bewildering impact on identity. She then explores and evaluates how the facility responded to this altered family relationship. While family members generally had unlimited access and privacy when visiting, there were few programmes specifically concerned with their needs. One critical issue is the orientation of the facility - should it be residentcentred or family-centred? She is critical of resident-centred government policy because it runs the risk of seriously limiting the role of the family to resource and ancillary functions. She concludes with an appeal for various measures, such as bridging programmes and access to counselling and support groups, to be introduced to enhance support of the family in residential settings. 


\section{John McCormack}

Women's Issues in Asia are covered in three papers which emerged from a 1994 conference in Singapore. While covering the same core issues of rapid population ageing, the tradition of familial support and the negative impacts on women, the papers reveal some interesting cultural differences. In the first paper about Korea, Suh points out that although sons are being seen as equal partners with daughters for familial support, a far greater proportion of older women prefer to be cared for by the son. The irony of this preference is however that it is the daughters-in-law who do the actual caring. Reporting on the Philippines situation, Domingo explains that the kinship system is traced bilaterally rather than patrilineally, and expressed care preferences by older women (and men) favour daughter care. Chayovan, reporting on Thailand, indicates that elderly co-residence with at least one child is so high $(77 \%)$ that no preference is evident. This is another interesting contrast: both the Korean and Philippine papers raise the issue of increasing proportions of elderly people living alone, currently nine and four per cent respectively. The focus on older women and their daughters is consistent across the three papers; common areas of concern include: the potentially increasing burden on daughters and the increasing proportions of widows, many of who are financially insecure due to low income, poor health and rural isolation as the young migrate to cities. These conditions are among the reasons why rapid population ageing is a significant challenge in Asia.

The final section concerns the Dynamics of Care-giving. A paper by Ranzijn and Luszcz examines the importance of parent-child contact to well-being. Using the first wave of data from the Australian Longitudinal Study of Ageing, they tested hypotheses that satisfaction with contact would predict well-being for the total sample, and that frequency of contact would add to this prediction for elderly people living alone. Of the initial I $992 / 93$ sample of 2,087, 93 per cent had one or more child living and 22.5 per cent lived alone. Depression and morale scales were used to measure well-being. Overall, they found high levels of well-being to be associated with contact satisfaction, although those living alone had slightly lower scores. As in previous research, frequency of contact was not significantly related to either depression or morale, except for those living alone. The authors argue the importance of examining sub-groups. They also mention that the small size of these particular effects is consistent with previous studies which suggest that the well-being of elderly people is multi-dimensional and that they possess many other means of maintaining well-being. In the second paper, Hohaus and Caird report on a preliminary study using three focus groups to examine the attitudes and opinions of 
middle-aged men and women to care-giving for elderly parents. There was considerable commonality across the groups in support of familial care but also an awareness of the potential difficulties of co-resident care. Only one group suggested that men could provide care while the other two thought daughters were more 'natural' carers. The authors thus suggest further research regarding the roles of sons in care-giving.

The final paper by Schulz and others examines the efficacy of a psycho-educational programme designed by the authors to assist family care-givers of elderly people. The programme involved nine sessions of $2 \frac{1}{2}$ hours in small groups. The evaluation tested firstly the effectiveness of fully accredited teachers versus those in training, and secondly, the programme outcomes for treatment and control groups. An Affect Balance Scale and an Anxiety Inventory Scale were used for pre- and post-testing. The failure to find differences in teacher effect was attributed to the initial high anxiety state of participants with either type of teacher. The second comparison however found that the treatment group scored higher and positively. The authors conclude that such programmes, which provide emotional and psychological support, are an essential component of the package of services needed by family care-givers.

\section{COMMENT}

This Family issue of the $A \mathcal{J} A$ has much of interest for everyone in gerontology because it is dealing with one, if not the most, fundamental institution in our society. The editor is to be congratulated not only for providing a broad sweep of family and ageing issues, but also for publishing in The Year of the Family. A strong theme running through most articles is the care of old people and how this affects family members. This focus may be indicative of the ageing and family priorities of the researchers who responded to the call for papers. This would not be surprising as the history of ageing in Australia has largely focused on their care and the family has been the primary basis of this support. Indeed the current focus of government reinforces this 'supplementation not substitution' model, and the role of care-givers has been given increased recognition in funding.

Viewing the family from a broader perspective, it is disappointing that there is no paper on the role of grandparents, to highlight the valuable contributions which older people make to families and to reinforce the fact that not all elderly people need to be cared for. Of more concern, however, is that the emphasis in most papers is on the negative aspects of care-giving without any mention of the positive 


\section{John McCormack}

benefits to care-givers themselves. As the editor of the journal has warned elsewhere, characterising care-giving as solely burdensome could lead to denigration of the task and the recipients. Many other family and ageing topics could of course have been included. Of interest to this writer would have been something on ageing issues in indigenous families, the family structures and roles of ageing babyboomers in the next century, and the economics of ageing for families. Further, although some papers make explicit reference to older people's filial care-giver preference, it might have been interesting to read more about older people's preferences for formal services vis-à-vis family support.

The extensive and, on occasion, acrimonious debate in Australia on its very definition shows that we are not yet 'one big happy family'. However, elderly people are now clearly being considered in this debate rather than seen as separate from it. This issue of the $A J A$ makes a timely contribution to the diversity of that discussion.

School of Social Work, University of Melbourne

\section{Health Services Reform}

The Reform of Health Care Systems. A Review of Seventeen OECD Countries, Health Policy Studies No. 5, OECD, Paris, 1994, 340 pp., no price, ISBN 9264 I 42509 .

Most industrialized countries have recently undergone, or are currently planning or implementing, health care reform in order to address endemic problems associated with financing and delivering health services. Such problems have been further exacerbated in recent times by reduced rates of economic growth, ageing populations and the continued development of medical technology. This publication is therefore a useful overview of how seventeen countries within the OECD have tackled such problems. The report is in two parts. Part I gives an overview of the changes that have taken place in the countries under review and attempts to draw conclusions about general trends in policy development. Part II provides, in individual chapters, more detail about each country's reform packages.

A classification of health care systems is presented in the Introduction, which is designed to aid the discussion in subsequent chapters. It is recognised that no neat classification is possible as 